\title{
Qualidade da tora e da madeira de clones de Eucalyptus para utilização na indústria de madeira serrada
}

\author{
Morgana Cristina França ${ }^{1 \star}$, Cláudio Gumane Francisco Juízo ${ }^{1}$, Márcio Pereira da Rocha ${ }^{1}$, Ricardo Jorge \\ Klitzke1, José Reinaldo Moreira da Silva², José Luiz Ferraresso Conti Junior³, Ana Gabriela Monnerat \\ Carvalho Bassa ${ }^{3}$
}
${ }^{1}$ Departamento de Engenharia Florestal, Universidade Federal do Paraná, Curitiba, PR, Brasil. ${ }^{2}$ Departamento de Ciências Florestais, Universidade Federal de Lavras, Lavras, MG, Brasil.
${ }^{3}$ Arborgen Tecnologia Florestal, Campinas, SP, Brasil.

\begin{abstract}
RESUMO O estudo foi desenvolvido para avaliar o potencial de cinco novos clones de eucalipto para a produção de madeira serrada. Foram utilizadas toras de três clones do híbrido Eucalyptus grandis x Eucalyptus urophylla, um clone de Eucalyptus grandis e um clone de Eucalyptus urophylla. Em todos os materiais genéticos foram avaliados a porcentagem de cerne, o índice de rachaduras de topo das toras e das tábuas, o arqueamento e o encurvamento verde e seco nas tábuas. Houve influência significativa dos clones na qualidade das toras e na qualidade da madeira serrada. Para o arqueamento (verde e seco) e encurvamento (verde) todos os clones foram classificados com empenamento leve. Após o desdobro, os clones 3 (Eucalyptus grandis $\mathrm{x}$ Eucalyptus urophylla), clone 4 (Eucalyptus grandis) e clone 5 (Eucalyptus grandis $\mathrm{x}$ Eucalyptus urophylla) apresentaram rachadura leve. Sendo assim, os clones 3 , 4 e 5 mostraram-se como potenciais fontes de matéria prima para produção de madeira serrada.
\end{abstract}

Palavras-chave: Qualidade da tora; Qualidade da madeira; Processamento da madeira.

\section{Quality of the log and wood of Eucalyptus clones for use in lumber industry}

\begin{abstract}
The study was conducted to evaluate the potential of five new eucalyptus clones for lumber production. Logs of three clones of the hybrid of Eucalyptus grandis $\mathrm{x}$ Eucalyptus urophylla, one clone of Eucalyptus grandis and one clone of Eucalyptus urophylla were used. In all genetic materials were evaluated the core percentage and the top splits index for the logs and the spring, bow and splits for the green and dry boards. The clones had a significant influence on the logs and lumber quality. Considering spring (green and dry) and bow (green), all clones were classified with light warping. After sawing, the clone 3 (Eucalyptus grandis $\mathrm{x}$ Eucalyptus urophylla), clone 4 (Eucalyptus grandis) and clone 5 (Eucalyptus grandis $\mathrm{x}$ Eucalyptus urophylla) presented light splits. Therefore, the clones 3, 4 and 5 proved to be potential sources of raw material for lumber production.
\end{abstract}

Keywords: Log quality; Wood quality; Wood processing.

\section{Introdução}

Entre as espécies plantadas que abastecem a indústria madeireira no Brasil, o eucalipto está entre as mais importantes, devido a taxa de crescimento, facilidade de implantação em grandes maciços, rusticidade e também pela gama de aplicações de sua madeira (LATORRACA et al.,
2015). A grande parte destas espécies são resultado do melhoramento genético e clonagem de material, uma operação que tem se tornado uma das principais opções para o aumento simultâneo da produção e melhoria da qualidade da madeira, controlando a expressão das características de interesse (BOTREL et al., 2007). 
No entanto, um dos grandes problemas da utilização do eucalipto são as tensões de crescimento, que são características intrínsecas ao crescimento natural das árvores e podem ocorrer tanto em folhosas como em coníferas. As tensões servem para manter a árvore de pé devido ao peso de sua copa e ações de agentes externos como ventos e relevo. Após a derrubada das árvores e o traçamento do tronco ocorre a liberação das tensões de crescimento, que são aliviadas parcialmente, ocasionando a maioria das rachaduras e deformações na tora (LIMA; STAPE, 2017).

Estas deformações podem se tornar um fator de redução da qualidade da madeira serrada por surgimento de rachaduras e empenamentos, além do cerne quebradiço, que fazem com que o produto seja depreciado durante e depois do processamento mecânico (PEDRO et al., 2014). Outro aspecto são as dificuldades operacionais que estes defeitos podem causar durante o processamento, isso faz com que seja importante a seleção de material com menores níveis de tensão de crescimento (CARVALHO et al., 2010).

Porém, entre as espécies de eucalipto, a intensidade das tensões de crescimento que se observam nas toras após a derrubada das árvores e nas tábuas durante as operações de desdobro em serraria é altamente variável, sendo que, em algumas a liberação da tensão é mais lenta do que em outras. Dessa maneira, algumas operações silviculturais, como desbaste ou ampliação do prazo de rotação podem reduzir os seus efeitos na madeira (SHIELD, 1995).

Tratos silviculturais envolvendo adubação, desrama e desbastes já foram testados e se comprovaram eficientes para melhorar a qualidade da matéria prima. No entanto, o aprimoramento de técnicas de desdobro e de secagem da madeira, aliados ao melhoramento genético visando produção de madeira maciça, são fundamentais para a obtenção de melhor qualidade da madeira serrada de espécies de rápido crescimento com acentuados níveis de tensões de crescimento.

Neste sentido, foi desenvolvido este estudo para avaliar o potencial de cinco novos clones de eucalipto para a produção de madeira serrada, avaliando a qualidade da tora e da madeira serrada por meio da porcentagem de cerne, índice de rachadura das toras e das tábuas, além dos empenamentos nas tábuas verdes e secas.

\section{Material e Métodos}

No presente estudo foi utilizado material genético da clonagem de eucalipto de um plantio experimental clonal com 10 anos de idade, localizado na cidade de Mogi Guaçu/SP, com o intuito de potencializar a indústria e o mercado de madeira serrada. Os clones foram desenvolvidos para a utilização na indústria de celulose e papel, porém em virtude do crescimento, tronco retilíneo e diâmetro, os clones foram destinados para avaliação dos seus potenciais como madeira serrada.

Assim, foram selecionados cinco clones, dos quais foram escolhidas e derrubadas cinco árvores de cada clone, levando em consideração o diâmetro altura do peito, forma do tronco e aspecto fitossanitário. Após a derrubada, as árvores foram traçadas, retirando-se duas toras com $2 \mathrm{~m}$ de comprimento em cada árvore, sendo que a primeira tora foi obtida a 4,5 m da altura total do fuste e a segunda tora foi obtida a $6,5 \mathrm{~m} \mathrm{da}$ altura total do fuste, totalizando assim 10 toras por clone e 50 toras para os cinco clones avaliados.

Em seguida as toras de cada clone foram devidamente identificadas e separadas, para mensuração do diâmetro e comprimento das mesmas, que posteriormente foram avaliadas as suas qualidades por meio de porcentagem de cerne e índice de rachadura, antes de serem submetidas ao desdobro para avaliação da qualidade das tábuas. 
Na Tabela 1 estão apresentados os valores dos diâmetros médios das toras de cada posição da árvore, procedência das árvores matrizes e o ano de coleta das procedências dos cinco clones de eucalipto utilizados para as avaliações.

\section{Qualidade das toras}

A avaliação do porcentual de cerne nos clones, foi realizada em disco retirados a $0,10 \mathrm{~m}, 2,5 \mathrm{~m}, 4,5 \mathrm{~m}$ e $6,5 \mathrm{~m}$ da altura total da árvore, conforme apresentado na Figura 1. Para tanto foram mensurados os dados dendrométricos de cada disco (diâmetro do disco e diâmetro do cerne), que foram utilizados para determinar a área total do disco e a área do cerne para posterior cálculo da porcentagem de área do cerne em relação a porcentagem de área do disco.

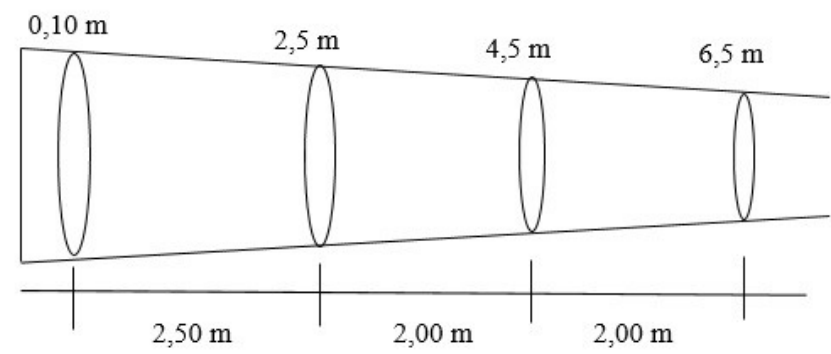

Figura 1. Posição da retirada dos quatro discos e das toras dos cinco clones.

Figure 1. Removing position of the four disc and logs of the five clones.

O índice de rachadura no topo das toras, foi determinado nas toras 2 e 3 (Figura 1) com o auxílio da metodologia proposta por Lima et al. (2007), sendo mensurado todos os comprimentos e espessuras das rachaduras na ponta fina e na ponta grossa de cada tora para posterior cálculo médio por tora. Em seguida, os índices de rachadura de topo das toras dos clones foram classificados em baixo $(\leq 0,8 \%)$, médio $(0,81$ a $1,3 \%)$ e alto $(\geq 1,31 \%)$, adaptando a metodologia utilizada por Cunha et al. (2015).

\section{Qualidade das tábuas}

As toras 2 e 3 de cada clone previamente avaliadas e cubadas foram reduzidas em semi-bloco em uma serra circular dupla para retirada de duas costaneiras, posteriormente, o semi-bloco foi desdobrado em serra circular multilâmina de um eixo, com 8 serras, obtendo-se tábuas radiais e tangenciais com dimensões nominais de 120 x 28 x $2000 \mathrm{~mm}$, (largura, espessura e comprimento, respectivamente).

A avaliação da qualidade das tábuas obtidas foi realizada por meio de empenamentos e índice de rachadura em tábuas recém desdobradas (tábuas verdes) e em seguida fazendo as mesmas avaliações nas mesmas tábuas submetidas a pré secagem ao ar livre até $20 \%$ de umidade (tábuas secas). A pilha da pré secagem ao ar livre foi montada sobre blocos de concreto com travessas de madeira a uma altura $30 \mathrm{~cm}$ do solo. A disposição da pilha seguiu a orientação dos ventos predominantes no local. Utilizou-se na cobertura 4 telhas de

Tabela 1. Procedência de clones e diâmetros médios das toras de eucalipto avaliadas.

Table 1. Headquarters of the clones and average diameters of eucalyptus logs assessed.

\begin{tabular}{ccccc}
\hline Clone & \multicolumn{1}{c}{ Espécie } & Procedência & Ano de coleta & Diâmetro (cm) \\
\hline 1 & $\begin{array}{l}\text { Eucalyptus grandis } \mathrm{x} \\
\text { Eucalyptus urophylla }\end{array}$ & Seleção massal & 2003 & 29,86 \\
\hline 2 & Eucalyptus urophylla & Seleção massal & 24,16 & 26,66 \\
\hline 3 & $\begin{array}{l}\text { Eucalyptus grandis } \mathrm{x} \\
\text { Eucalyptus urophylla }\end{array}$ & $\begin{array}{l}\text { Polinização } \\
\text { controlada }\end{array}$ & 2004 & 20,58 \\
\hline 4 & Eucalyptus grandis & Seleção massal & 2002 & 22,00 \\
\hline 5 & $\begin{array}{l}\text { Eucalyptus grandis } \mathrm{x} \\
\text { Eucalyptus urophylla }\end{array}$ & Seleção massal & 2003 & 2 \\
\hline
\end{tabular}


fibra-cimento, diminuindo dessa forma a incidência de raios solares e de precipitações diretamente na madeira, além disso a cobertura foi pregada em uma armação com o objetivo de promover a restrição mecânica das tábuas.

Assim sendo, os empenamentos avaliados foram o arqueamento, encurvamento e encanoamento. Neste contexto foram mensurados os comprimentos das tábuas verdes e secas, tendo-se em seguida medidos os desvios das tábuas causados pelos devidos empenamentos em relação ao comprimento da tábua, segundo a metodologia de Latorraca et al. (2015).

Salienta-se que o encanoamento foi descartado na qualificação da madeira dos clones por este ser muito baixo e não ter muita influência na qualidade da madeira. Em seguida determinou-se o índice de rachaduras das tábuas pela medição do comprimento das maiores rachaduras nos topos de cada peça em relação ao comprimento total da tábua como proposto por Latorraca et al. (2015). Finalmente, os valores obtidos, foram utilizados, para a classificação da qualidade da madeira serrada de cada clone de acordo com o estudo realizado por Severo (2000).

\section{Análise dos dados}

Os dados foram tabulados no pacote estatístico Excel, onde foram gerados gráficos para análise da variação do porcentual de cerne e índice de rachadura dos clones. Em seguida utilizou-se o programa Statgraphics Centurion XVI.I, para análise de variância simples (ANOVA) para a qualidade das toras e da madeira serrada verde e seca de cada clone. Para efeito fez-se um delineamente inteiramente ao acaso para qualidade das toras e da madeira serrada, considerando os clones como fonte de variação. Confirmada a rejeição da hipótese nula para a ANOVA, aplicou-se o teste de Tukey para a comparação das médias de qualidade de madeira verde e seca a $95 \%$ de nível de confiança.

\section{Resultados e Discussão}

\section{Qualidade das toras}

Observa-se que os clones 1 e 4 apresentaram a porcentagem de cerne estatisticamente superior aos demais clones, além disso o clone 5 apresentou menor porcentual de cerne, com diferenças significativa em relação aos demais clones (Figura 2).

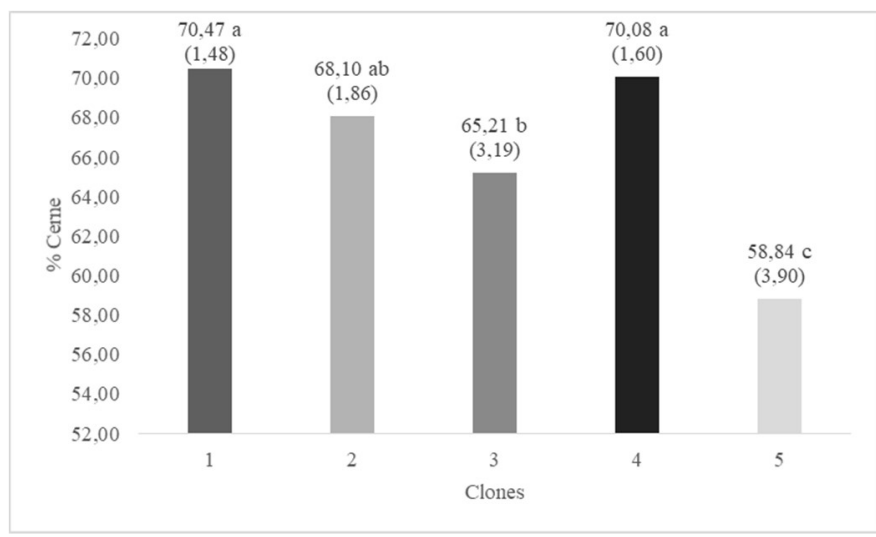

Médias seguidas pela mesma letra não diferem entre si (Tukey, p>0,05); entre parênteses segue o desvio padrão.

Figura 2. Variação da porcentagem de cerne (\%) das toras de cinco clones de eucalipto.

Figure 2. Variation of the core percentage (\%) of the logs of the five eucalyptus clones.

De uma forma geral, os valores percentuais de cerne dos cinco clones foram relativamente elevados e considerados satisfatórios para produtos sólidos, uma vez que os mesmos evidenciam maior percentual de madeira de boa qualidade e com isso maiores rendimento em madeira de maior resistência e durabilidade. Os valores observados para os 5 clones foram inferiores as observações feitas por Lopes et al. (2004) para o Eucalyptus grandis aos 27 anos idade os quais observaram $75,6 \%$ na porcentagem de cerne.

Vale lembrar que quando se trata de florestas plantadas, o melhoramento genético e as atividades silviculturais, têm grande influência na qualidade da madeira sólida. Além da clonagem, Gonçalves et al. (2010) corrobora que as operações de espaçamento, redução da densidade de plantio e desrama, 
podem ter influenciado na variabilidade e bom desenvolvimento dos clones avaliados, uma vez que os mesmos tiveram maior percentual de madeira de cerne que, teoricamente, é vista como tendo maior massa específica e mais resistente em comparação com as matrizes atualmente utilizadas na indústria de produção de madeira serrada.

A variação do percentual de cerne é uma característica genética e silvicultural, que influencia diretamente na redução de tensão de crescimento, por apresentar maior estabilidade na madeira, e com isso na intensidade de rachaduras e qualidade da tora derrubada. Além do percentual de cerne, melhoramento genético e adequadas técnicas de desdobro, Braz et al. (2016) complementam que a qualidade do sítio, práticas silviculturais e manejo adequados ajudam a reduzir as tensões de crescimento, porém, o presente estudo não observou tal comportamento. Assim sendo, na Figura 3 vem ilustrado o índice de rachadura de topo das toras ( $\mathrm{IRT}_{\text {tora }}$ em \%) obtidos para os cinco clones de eucalipto avaliados.

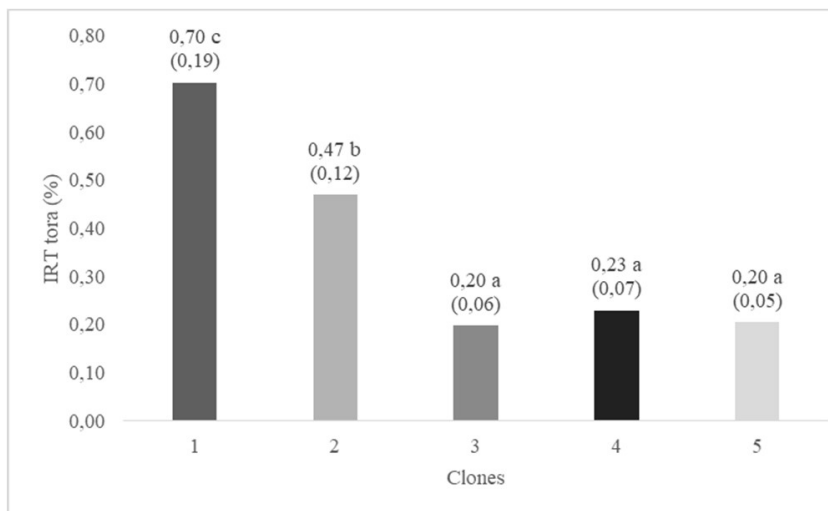

Médias seguidas pela mesma letra não diferem entre si (Tukey, p >0,05); entre parênteses segue o desvio padrão.

Figura 3. Variação do índice de rachadura de topo (IRT tora \%) dos cinco clones de eucalipto.

Figure 3. Variation of the top crack index $\left(\operatorname{IRT}_{\text {tora }} \%\right)$ of the five eucalyptus clones.

Ao contrário do que se observou com o porcentual do cerne, o índice de rachadura variou bastante entre as clones. É possível observar na Figura 3, que os clones 3, 4 e clone 5, tiveram valores de índice de rachadura estatisticamente iguais e por sua vez os mesmos foram estatisticamente diferentes dos clones 1 e clone 2, que apresentaram maiores índices de rachaduras de topo nas toras.

Apesar de terem a mesma idade, o clone 1 teve um desenvolvimento mais rápido resultando nas toras de maiores diâmetros em relação aos demais clones. E que mesmo tendo maior porcentual de cerne que é uma caracteristica indicativa de qualidade da madeira, o rápido crescimento possivelmente resultou na maior concentração de tensão de crescimento em resultado do desenvolvimento rápido das células de formação do tronco no câmbio, tornando-as instáveis depois da derrubada.

Não obstante, Braz et al. (2016) complementa que maiores taxas de crescimento proporcionaram maior desenvolvimento das tensões de crescimento e consequentemente maiores índices de rachaduras em toras de maiores diâmetros.

Em relação ao índice de rachadura dos cinco clones, foram observados valores inferiores aos resultados de Lima et al. (2007), quando avaliaram a influência do desbaste e da fertilização em algumas propriedades de toras de Eucalyptus grandis de 21 anos de idade, variando de 0,72 a 0,89\%.

No entanto, Trevisan et al. (2013), cobrindo os topos das toras de Eucalyptus grandis com 18 anos com saco plástico, obteve valores de índices de rachaduras das toras mais elevados em relação aos encontrados no presente estudo, que foram de 1,2 a 1,7\% para árvores centrais e dominantes, respectivamente. Isso nos leva a considerar os índices de rachaduras obtidos neste estudo, como sendo baixos, conforme também demostrado na classificação proposta, sendo menores do que $0,80 \%$, indicando mais uma vez o potencial desses materiais clonais para utilização das toras na produção de madeira serrada. 


\section{Qualidade da madeira serrada}

Observa-se na Tabela 2, que tanto nas tábuas verdes assim como para as tábuas secas, os diferentes clones avaliados tiveram efeito significativo na qualidade da madeira serrada. A diferença significativa encontrada nas tábuas verdes e secas dos clones pode estar relacionada com a variação genética entre os mesmos, pois, pelas variáveis dendrométricas medidas nas toras de cada clone, é possível observar que o clone 1 e o clone 3 tiveram maiores crescimentos no diâmetro em relação aos demais clones.

Essa diferença de crescimento diamétrico entre os clones, é resultado da diferença na velocidade de expansão lateral das células e de camadas de crescimento pela atividade cambial, conforme relatado por Husch et al. (1982), além disso Lamprecht (1990) acrescenta que o crescimento é influenciado pela genética da espécie. Apesar de ter como vantagem a obtenção de grandes volumes de madeira, esta é uma situação que acaba trazendo a origem das limitações observadas na utilização do eucalipto e da maioria de espécies de rápido crescimento como madeira serrada.

$\mathrm{Na}$ Tabela 3, pode-se observar que o os clones apresentaram médias diferentes estatisticamente para o arqueamento sendo que os clones 4 e 5 apresentaram peças com maiores flechas em relação aos demais. Além disso, vale destacar que os clones 1, 2 e 3, tiveram peças com arqueamento duas vezes menor, a cada milímetro por metro de madeira serrada, quando comparados aos clones 4 e 5 .

Isso indica que os ganhos genéticos, com o maior porcentual de cerne observado nas toras dos clones 1 , clone 2 e clone 3, contribuiram para a obtenção de peças mais estáveis após o desdobro, controlando assim o possível efeito das tensões de crescimento que se manisfestam em tábuas verdes.

De uma forma geral, os ganhos observados com a clonagem do eucalipto foram satisfatórios para o arqueamento das peças, uma vez que em estudo envolvendo Corymbia citriodora, Eucalyptus saligna e Eucalyptus tereticornis, com aproximadamente 25 anos, Stangerlin et al. (2009) encontraram valores médios para arqueamento após o desdobro de 2,59, 2,87 e 2,88 mm/m, respectivamente. Já, Cademartori et al. (2015), avaliando a eficiência de herbicida na redução dos efeitos das tensões de crescimento de Eucalyptus grandis com 16 anos, obtiveram valores que variaram de 0,81 a $1,24 \mathrm{~mm} / \mathrm{m}$. E ainda, Rocha; Tomaseli (2002) utilizando o anelamento e vaporização para redução das tensões de crescimento, obtiverem como valores médios para o Eucalyptus grandis com 12 anos, $0,15 \mathrm{~mm} / \mathrm{m}$ e 7,78 $\mathrm{mm} / \mathrm{m}$ e para o Eucalyptus dunnii com 16,5 anos, $0,23 \mathrm{~mm} / \mathrm{m}$ e $4,78 \mathrm{~mm} / \mathrm{m}$, para o desdobro tangencial e radial, respectiva-

Tabela 2. Resumo da análise de variância da qualidade das tábuas verdes e secas obtidas dos cinco clones de eucalipto.

Table 2. Summary of variance analysis for quality of the green and dry boards obtained from of the five eucalyptus clones.

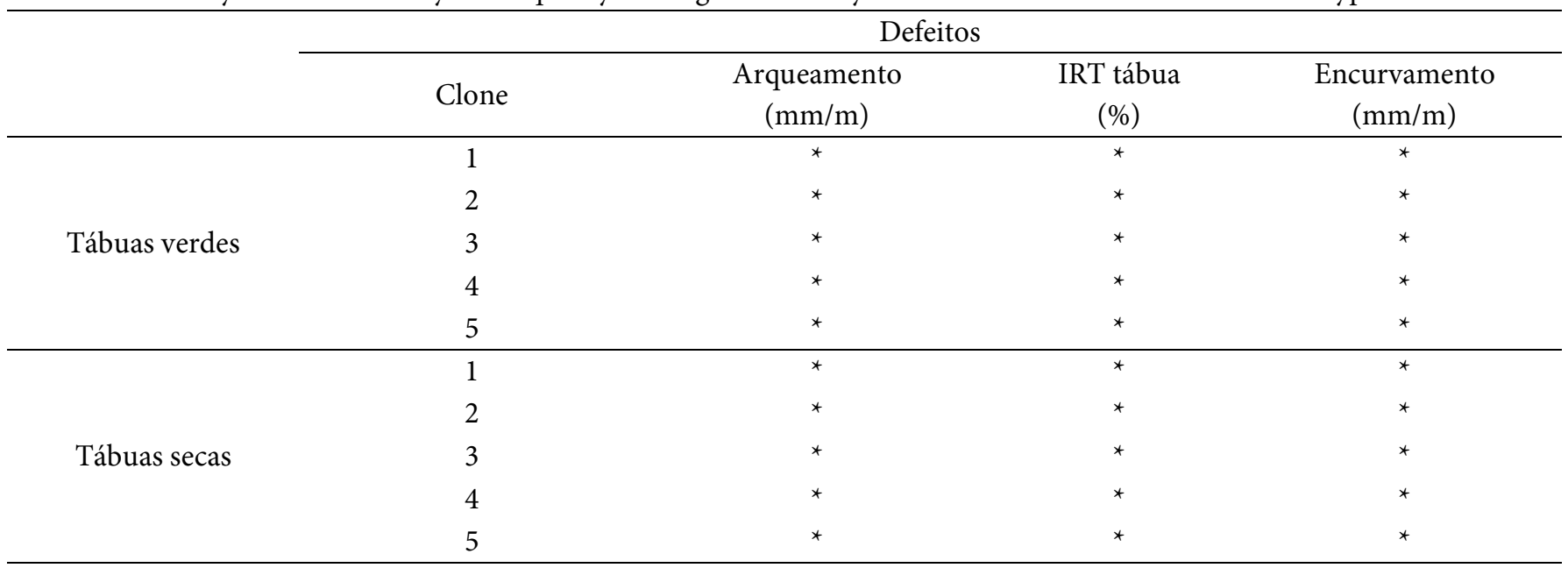

${ }^{\star}$ Significativo ao nível de $5 \%$ de probabilidade de erro $(0.01 \leq \mathrm{p}<0.05)$; ns: não significativo $(\mathrm{p} \geq 0.05)$. 
Tabela 3. Valores médios do arqueamento, encurvamento e índice de rachadura das tábuas verdes dos cinco clones de eucalipto. Table 3. Average values of bending, curving and cracks index of the green of the five eucalyptus clones.

\begin{tabular}{|c|c|c|}
\hline Defeito & Clone & Média \\
\hline \multirow{5}{*}{ Arqueamento $(\mathrm{mm} / \mathrm{m})$} & 1 & $0,51 \mathrm{a}$ \\
\hline & 2 & $0,47 \mathrm{a}$ \\
\hline & 3 & $0,58 \mathrm{a}$ \\
\hline & 4 & $1,06 \mathrm{~b}$ \\
\hline & 5 & $1,07 \mathrm{~b}$ \\
\hline \multirow{5}{*}{ Encurvamento $(\mathrm{mm} / \mathrm{m})$} & 1 & $1,22 \mathrm{a}$ \\
\hline & 2 & $2,27 \mathrm{bc}$ \\
\hline & 3 & $1,65 \mathrm{ab}$ \\
\hline & 4 & $3,15 \mathrm{~cd}$ \\
\hline & 5 & $3,64 \mathrm{~d}$ \\
\hline \multirow{5}{*}{$\operatorname{IRT}_{\text {tábua }}(\%)$} & 1 & $21,34 b$ \\
\hline & 2 & $18,11 \mathrm{~b}$ \\
\hline & 3 & $7,56 \mathrm{a}$ \\
\hline & 4 & $9,32 \mathrm{a}$ \\
\hline & 5 & $11,50 \mathrm{a}$ \\
\hline
\end{tabular}

Médias seguidas pela mesma letra na coluna não diferem entre si (Tukey, $\mathrm{p}>0,05)$

mente.

No encurvamento das peças obtidas após o desdobro, destaca-se mais uma vez o clone 1 com menor encurvamento, que foi três vezes menor em relação ao maior encurvamento que foi observado no clone 5. Era esperado que as peças dos clones 4 e 5 tivessem menores encurvamentos pelo fato de serem obtidas de toras de menores diâmetros, porém mais uma vez verifica-se a influência do tipo de lenho, pois o maior diâmetro das toras e porcentual de cerne nos clones 1 e clone 2, permitiram obter maior porcentual de peças com maior largura no sentido dos anéis de crescimento, o que as torna mais dificeis de encurvar.

Ainda assim os valores de encurvamento observado nos cinco clones são relativamente semelhantes aos valores encontrado por Stangerlin et al. (2009) e Rocha; Tomaseli (2002) e superiores aos encontrados por Cademartori et al. (2015).

Ainda na Tabela 3, os índices de rachaduras nas peças recém desdobradas, tiveram um comportamento diferente dos empenamentos, sendo que, nas toras de maiores diâmetros observaram-se maiores valores porcentuais em relação as toras de menor diâmetro que tiveram índices duas vezes menor. Essa situação indica que apesar das peças obtidas das toras de maiores diâmetros serem mais estáveis aos empenamentos, elas apresentaram maiores problemas de tensão de crescimento pelo rápido crescimento que tiveram.

Por outro lado, o fato das peças terem sido obtidas de toras maiores, as mesmas tiveram maiores larguras, no sentido dos anéis o que torna mais susceptíveis a surgimento de rachaduras depois do desdobro, situação que também foi observada por Trevisan et al. (2013) em toras de árvores matrizes de Eucalyptus grandis. No entanto, valores relativamente próximos, foram obtidos por Souza et al. (2012) os quais estimaram uma amplitude média de 15,1 a $23,7 \%$ no índice de rachadura da madeira serrada de Eucalyptus grandis.

Pode-se observar na Tabela 4, que a secagem das peças até $20 \%$ de umidade aumentou de forma considerável a 
proporção de defeitos na forma de arqueamento e encurvamento, sendo que o índice de rachadura praticamente manteve-se estável em relação as peças verdes.

$\mathrm{O}$ arqueamento de tábuas secas apresentou diferenças significativas entre os clones e foi classificado como arqueamento leve $(<5 \mathrm{~mm} / \mathrm{m})$, para todos os clones, de acordo com os parâmetros propostos por Severo (2000). O aumento observado após a secagem pode ser explicado pela ação das tensões residuais presente nas tábuas dos clones avaliados, semelhante a situação observada Duarte et al. (2015) quando secaram Eucalyptus sp. ao ar livre.

Assim sendo, os clones 1 e 2, que tiveram toras com maior crescimento, apresentaram maiores intensidades de tensões, resultando num aumento de aproximadamente 100\% dos valores de arqueamento em relação aos clones 4 e 5, que tiveram um crescimento gradual, reduzindo as tensões de secagem.

O encurvamento das tábuas após a secagem foi mais intenso, também com diferenças significativas entre os clones, superando os valores médios observados por Duarte et al. (2015), Stangerlin et al. (2009) e o enquadrando como encurvamento forte $(>5 \mathrm{~mm} / \mathrm{m})$ de acordo com Severo (2000). Não obstante, é possível observar que o encurvamento seco se manifestou na mesma proporção para os clones, chegando a ser aproximadamente sete vezes maior tanto em tábuas obtidas de toras de maiores diâmetros assim como em tábuas obtidas de toras de menores diâmetros.

Assim sendo, para este defeito, além das tensões residuais observadas nos clones, o peso colocado na parte superior da pilha pode ter sido insuficiente para causar restrição mecânica das peças, contrariamente ao que foi observado por Liebl et al. (2017). Portanto o encurvamento foi proporcional em todos clones, uma vez que a secagem foi feita de uma só vez, fazendo-se uma única pilha sem nenhum critério de separação dos clones.

A mesma situação não se observou no índice de rachaduras das peças, pois a secagem não foi prejudicial, possivelmente por se ter feito uma secagem lenta, ao ar livre,

Tabela 4. Valores médios do arqueamento, encurvamento e índice de rachadura das tábuas secas dos cinco clones de eucalipto. Table 4. Average values of the bending, curving and crack index of the dry boards of the five eucalypus clones.

\begin{tabular}{|c|c|c|}
\hline Defeito & Clone & Média \\
\hline \multirow{5}{*}{ Arqueamento (mm/m) } & 1 & $3,01 \mathrm{a}$ \\
\hline & 2 & $3,88 \mathrm{ab}$ \\
\hline & 3 & $4,03 \mathrm{~b}$ \\
\hline & 4 & $3,39 \mathrm{ab}$ \\
\hline & 5 & $3,68 \mathrm{ab}$ \\
\hline \multirow{5}{*}{ Encurvamento $(\mathrm{mm} / \mathrm{m})$} & 1 & $4,98 \mathrm{a}$ \\
\hline & 2 & $6,26 a b$ \\
\hline & 3 & $7,02 \mathrm{~b}$ \\
\hline & 4 & $6,43 \mathrm{ab}$ \\
\hline & 5 & $7,56 \mathrm{~b}$ \\
\hline \multirow{5}{*}{$\operatorname{IRT}_{\text {tábua }}(\%)$} & 1 & $22,29 \mathrm{~b}$ \\
\hline & 2 & $20,44 \mathrm{~b}$ \\
\hline & 3 & $10,37 \mathrm{a}$ \\
\hline & 4 & $12,82 \mathrm{a}$ \\
\hline & 5 & $14,10 \mathrm{a}$ \\
\hline
\end{tabular}

Médias seguidas pela mesma letra na coluna não diferem entre si (Tukey, $p>0,05)$. 
na qual a remoção de água e liberação de tensões residuais foi de forma branda. Assim sendo, houve aumento de aproximadamente $10 \%$ no porcentual de rachaduras das tábuas secas em comparação com as tábuas verdes, sugerindo assim que a maior parte das tensões observadas nos clones foram devido ao rápido crescimento, pois conforme relatado por Hornburg et al. (2012) há uma tendência significativa das rachaduras aumentarem com o diâmetro das toras.

De uma forma geral os valores dos parâmetros de qualidade da madeira observados nas tábuas verdes não comprometem a utilização destes clones como madeira serrada, pois os mesmos foram inferiores aos apresentados na literatura com estudos de espécies de maior idade e que ficaram mais tempo no plantio. Além disso, o curto período de rotação destes clones e a redução do custo operacional com atividades silviculturais, tornam esses clones uma boa alternativa e de baixo custo para a indústria de processamento de madeira.

\section{Conclusões}

A porcentagem de cerne não teve relação com o índice de rachaduras das toras. Os clones apresentaram arqueamento leve independentemente do teor de umidade das tábuas. Por outro lado, o encurvamento mostrou-se um parâmetro de influência significativa na qualidade da madeira após a secagem. O índice de rachadura nas tábuas foi mais pronunciado para os clones 3, 4 e 5. Mesmo assim, o clone 3, 4 e 5 mostraram-se como potenciais fontes de matéria prima para produção de madeira serrada. E os clones 1 e 2 podem ser potenciais para o mercado de madeira serrada quando forem devidamente manejados e com mais anos de plantio para a redução das tensões de crescimento.

\section{Referências}

BOTREL, M. C. G.; TRUGILHO, P. F. S.; ROSADO, C. S.; SILVA, J. R. M. S. Melhoramento genético das propriedades do carvão vegetal de Eucalyptus spp. Revista Árvore, Viçosa, v. 31, n. 3, p. 391-398, 2007.

BRAZ, R. L.; MATOS, J. L. M. DE; ROCHA, M. P. DA; PRATA, J. G. Relação entre a deformação residual longitudinal com crescimento e propriedades da madeira de espécies de Eucalyptus. Scientia Forestalis, Piracicaba, v. 44, n. 111, p. 629-640, 2016.

CADEMARTORI, P. H. G.; GATTO, D.A.; STANGERLIN, D.M.; MASTELLA, T.; VARGAS, J. F. ; SANTINI, E. J. Uso de herbicida na redução das tensões de crescimento na madeira serrada de Eucalyptus grandis. Ciência Florestal, Santa Maria, v. 25, n. 3, p. 801-808, 2015

CARVALHO, A. M; GONÇALVES, M. da P. M.; AMPARADO, K. de F.; LATORRACA, J. V. DE F.; GARCIA, R. A. Correlações da altura e diâmetro com tensões de crescimento em árvores de Corymbia citriodora e Eucalyptus urophylla. Revista Árvore, Viçosa, v. 34, n. 2, p. 323-331, 2010.

CUNHA, A. B da; FRANÇA, M. C.; ALMEIDA, C. C. F. de; GORSKI, L.; CRUZ, R. C. da; SANTOS, D. dos. Avaliação do rendimento em madeira serrada de Eucalyptus benthamii e de Eucalyptus grandis por meio do desdobro tangencial e radial. Floresta, Curitiba, v. 45, n. 2, p. 241 - 250, 2015.

DUARTE, M. M.; TREVISAN, R.; SUSIN, F.; ZEN, L.R. VALERIUS, J. Drying curve and defects of Eucalyptus sp. wooden submitted to air drying. Spanish Journal of Rural Development, v. 6, p. 161-170, 2015.

GONÇALVES, F. G.; OLIVEIRA, J. T. da S.; SILVA, F. da; NAPPO, M. E.; TOMAZELO FILHO, M. Parâmetros dendrométricos e correlações com propriedades tecnológicas em um híbrido clonal de Eucalyptus urophylla x Eucalyptus grandis. Revista Árvore, Viçosa, v.34, n.5, p.947-959, 2010.

HORNBURG, K. F.; ELEOTÉRIO, J. R.; BAGATTOLI, T. R.; NICOLETTI, A. L. Qualidade das toras e da madeira serrada de seis espécies de eucalipto cultivadas no litoral de Santa Catarina. Scientia Forestalis, Piracicaba, v. 40, n. 96, p. 463$471,2012$.

HUSCH, B.; MILLER, C. I.; BEERS, T. W. Forest mensuration. New York: Ronald, 1982. 401p. 
LAMPRECHT, H. Silvicultura nos trópicos. Eschborn: GTZ 1990. 343p.

LATORRACA, J. V. de; DIAS JÚNIOR, A. F.; SILVA, G. C.; PACE, J. H. C.; CARVALHO, A. M. de. Anelamento e vaporização de toras visando otimização do processo de secagem da madeira eucalipto. Revista Brasileira Ciências Agrárias. Recife, v.10, n.2, p.273-279, 2015.

LIEBL, O. A.; LOIOLA, P. L.; ZEN, L. R.; KLITZKE, R. J.; ROCHA, M. P. da. Influência dos Parâmetros Dimensionais da Pilha na Qualidade da Madeira de Eucalyptus spp. Submetida à Secagem ao Ar. Floresta Ambiente, Seropédica, vol. 24, 2017.

LIMA, I.L.; GARCIA, J.N.; STAPE, J.L. Influência do desbaste e da fertilização no deslocamento da medula e rachaduras de extremidade de tora de Eucalyptus grandis Hill ex Maiden. Cerne, Lavras, v.13, n.2, p.170-177, 2007.

LIMA, I. L. DE; STAPE, J. L. Caracterização da madeira serrada em clones de Eucalyptus. Pesquisa Florestal Brasileira, Colombo, v. 37, n. 89, p. 55-62, 2017.

LOPES, M. C.; HASELEIN, C. R.; SANTINI, E. J.; LONGHI, S. J.; ROSSO, S.; FERNANDES, D. L. G.; MENEZES, L. F. Agrupamento de árvores matrizes de Eucalyptus grandis em função das variáveis dendrométricas e das características tecnológicas da madeira. Ciência Florestal, Santa Maria, v.14, n.2, p.133-144, 2004.

PEDRO F.S.; JUIZO C.G.F.; ROCHA M.P.; BILA N.F.; UETIMANE E., Avaliação do Rendimento em Madeira Serrada de Eucalipto para Dois Modelos de Desdobro numa Serraria Portátil. Floresta e Ambiente, Seropédica, v.21, n.4, p.543-550, 2014.

ROCHA, M. P.; TOMASELLI, I. Efeito do modelo de desdobro na qualidade da madeira serrada de Eucalyptus grandis e Eucalyptus dunnii. Cerne, Lavras, v. 8, n. 2, p. 70$83,2002$.

SEVERO, E. T. D. Qualidade da secagem de madeira serrada de Eucalyptus dunnii. Ciência Florestal, v.10, n.1, p.109-124, 2000.

SHIELD, E.D. Plantation grown eucalyptus: utilization for lumber and rotary veneers - primary conversion. In: Seminário international de utilização da madeira de eucalipto para serraria. Anais... IPEF/IPT/ IUFRO/LCF-ESALQ-USP. São Paulo, p.133-139, 1995.
SOUZA, J. T.; TREVISAN, R.; DENARDI, L.; STANGERLIN, D. M.; VIVIAN, M. A.; HASELEIN, C. R.; SANTINI, E. J. Qualidade da Madeira serrada proveniente de árvores dominantes e médias de Eucalyptus grandis submetidas à secagem. Cerne, Lavras, v. 18, n. 1, p.167-174, 2012.

STANGERLIN, D. M.; SANTINI, E. J.; SUSIN, F.; MELO, R. R.; GATTO, D. A.; HASELEIN, C. R. Uso de estufa solar para secagem de madeira serrada. Ciência Florestal. Santa Maria, v.19, n.4, p.461-472, 2009.

TREVISAN, R.; DENARDI, L.; CARDOSO, G. V.; HASELEIN, C. R.; SANTINI, E. J. Variação axial do índice de rachaduras na base e no topo de toras de Eucalyptus grandis W. Hill ex Maiden. Scientia Forestalis, Piracicaba, v. 41, n. 97, p. 075-081, mar. 2013. 